\title{
Mortality from myocardial infarction in different types of hospitals
}

\author{
ROBERT REZNIK，IAN RING， PETER FLETCHER，GEOFFREY BERRY
}

\begin{abstract}
Hospitals ranging from large urban teaching hospitals to small country hospitals were stratified into four levels of care and examined for their effectiveness of coronary care in relation to these levels. The crude hospital mortality among 2265 patients admitted for definite or possible acute myocardial infarction was $21 \%$ at level 1 (the most elaborate level), $22 \%$ at level 2, $21 \%$ at level 3, and $19 \%$ at level 4 (the least elaborate). Adjustment for age or other prognostic factors produced no significant differences across levels either for coronary care unit care or for combined coronary unit and ward care. Success in resuscitation was also similar across levels.

These findings suggest that increased resources for coronary care units-whether for new services or for upgrading existing ones-may not be required.
\end{abstract}

\section{Introduction}

The effectiveness of coronary care units in reducing hospital mortality in patients with acute myocardial infarction remains controversial. ${ }^{1}$ The relative effectiveness of different levels of refinement of coronary care facilities is of concern to health care planners and clinicians. For instance, do people admitted to the

Department of Community Medicine, Royal Prince Alfred Hospital, Camperdown, Sydney, Australia

ROBERT REZNIK, MB, BS, deputy director

Cancer Epidemiology and Prevention Unit, Queensland Department of Health, Queensland

IAN RING, MPH, MSC, director

Department of Medicine, University of Sydney, Sydney

PETER FLETCHER, FRACP, PHD, senior lecturer

School of Public Health and Tropical Medicine, University of Sydney, Sydney

GEOFFREY BERRY, MA, FIS, associate professor of biostatistics

Correspondence to: Dr R Reznik, Department of Community Medicine, Royal Prince Alfred Hospital, Glebe, 2037 Australia. most elaborate types of care fare better than those admitted to hospitals which have more basic facilities? We have compared hospital mortality and the effectiveness of cardiopulmonary resuscitation among hospitals which represented the range of acute care facilities for patients admitted with suspected myocardial infarctions.

\section{Hospitals, patients, and methods}

The study was conducted in 18 public hospitals ( 13 in New South Wales, five in Queensland) between May 1979 and October 1980. The hospitals were stratified into four levels depending on the degree of refinement of their coronary care unit facilities (table I). The level of refinement varied from a

TABLE $\vdash$ Criteria defining level of care

\begin{tabular}{lcccc}
\hline & Level 1 & Level 2 & Level 3 & Level 4 \\
\hline Continuous monitoring & + & + & + & \pm \\
Certified trained coronary care nursing staff & + & + & \pm & \pm \\
$\begin{array}{l}\text { Nursing staff delegated to provide emergency } \\
\quad \text { care }\end{array}$ & + & $\pm^{\star}$ & \pm & \pm \\
$\begin{array}{l}\text { Staff cardiologist } \\
\text { Cardiac surgical service }\end{array}$ & + & \pm & - & -
\end{tabular}

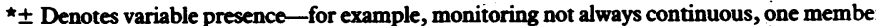
of rotating nursing staff with some certification, nursing staff sometimes delegated to emergency.

large metropolitan teaching hospital (level 1) to a small country district hospital (level 4). The most elaborate units had monitoring equipment connected to alarms and a central control display manned continuously by specially trained nursing sisters, who were often responsible for initiating treatment using established unit protocols. They had the services of a unit cardiologist who worked within the hospital, and in the case of level 1 care they also had the services of cardiac surgical teams for emergency surgery. In contrast with this was the designated unit care of the level $\mathbf{4}$ hospital. This consisted of part of a medical ward with portable monitors, usually staffed by comparatively inexperienced nurses. Though such hospitals often had a visiting physician, most cases were managed by the general practitioner, and these hospitals had far fewer acute admissions (usually fewer than 100 a year). 
The study enrolled 2991 patients with suspected myocardial infarction. To avoid possible selection bias the following procedure was adopted by the person gathering data at each hospital. Hospital admissions were reviewed on a daily basis and the criteria for recruitment based on the recommendations for acute myocardial infarction registers. ${ }^{2}$ Entry to the study was based on a clinical presentation suggesting myocardial infarction, such as acute chest pain, dyspnoea, collapse, or related symptoms. At each hospital electrocardiographic reports, laboratory cardiac enzyme results, and hospital deaths from cardiovascular disease were systematically reviewed on a daily basis for other potential subjects. Every six weeks the hospital records of deaths and discharges of patients with diagnoses coded ICD (9th revision) 410-414 were reviewed independently to ensure that no possible patients had been missed. There was no age limit, but patients were excluded if their infarction occurred as a complication of another condition which had precipitated admission.

Each patient was interviewed by a study sister within 48 hours of admission to determine the history of the attack and past medical history. Details were confirmed by reference to appropriate sources. Only nine possible attacks (one case was excluded because a prognostic score could not be calculated).

There were no significant differences among levels for the main clinicat and demographic characteristics of the patients. Their mean age was 64 years, and $1562(69 \%)$ were men. Clinical factors associated wit ischaemic heart disease included 722 patients $(32 \%)$ with a positive familo history, 822 (36\%) who were current smokers, 1045 (46\%) with past angina $636(28 \%)$ with past infarction, $871(38 \%)$ with hypertension, $202(9 \%)$ wit diabetes, and $156(7 \%)$ with past congestive cardiac failure.

Chest pain was the presenting symptom in 1790 patients (79\%). II 1696 cases $(75 \%)$ the attack was considered to be typical. On presentation to hospital the average pulse rate was 84 beats/min and average systolic bloof pressure $141 \mathrm{~mm} \mathrm{Hg}$. Six hundred and eighty patients $(30 \%)$ had evidence of right or left heart failure but only $91(4 \%)$ were in shock. There were $n$. significant differences in these clinical signs across levels. An importare variable was the time from attack to presentation at hospital. In patien whose time of onset of the attack was known the delay was similar at eact level (figure). There were 1997 patients (88\%) with a known time of onse

TABLE II-Distribution of levels of care among patients of various diagnostic groups. Figures are numbers (percentages) of patients

\begin{tabular}{lccccc}
\hline & Level 1 & Level 2 & Level 3 & Level 4 & Total \\
\hline Definite acute myocardial infarction & $450(63)$ & $616(62)$ & $430(55)$ & $274(56)$ & $1770(59)$ \\
Possible acute myocardial infarction & $127(18)$ & $159(16)$ & $142(18)$ & $68(14)$ & $496(17)$ \\
No acute myocardial infarction & $138(19)$ & $221(22)$ & $215(27)$ & $145(30)$ & $719(24)$ \\
Insufficient data & $1(0 \cdot 1)$ & $3(0 \cdot 3)$ & $1(0 \cdot 1)$ & $1(0 \cdot 2)$ & $6(0 \cdot 2)$ \\
\hline Total & $716(100)$ & $999(100)$ & $788(100)$ & $488(100)$ & $2991(100)$ \\
\hline
\end{tabular}

patients refused to participate. For patients who had died without interview information was obtained from relatives or other sources. Details of hospital management were obtained from the medical record and from an attending physician when necessary. The history of attack, cardiac enzyme values, and electrocardiogram recordings for each subject were reviewed centrally and blindly by an independent physician. Patients were classified as having definite, possible, or no myocardial infarction or insufficient data by World Health Organisation criteria, ${ }^{2}$ the criteria for a possible case being based on an alternative WHO definition. ${ }^{3}$ Any case in which discrepancies arose in classification was reviewed by an independent panel.

Patients were further classified into either unit or ward care groups. This was based on the predominant site of care during the initial $\mathbf{4 8}$ hours after admission. Patients who died within 48 hours were assigned to the site where most of their time was spent (excluding the casualty department).

The expected hospital death rates used to estimate sample size were $7 \%$ (level 1), 14\% (level 2), 24\% (level 3), and 35\% (level 4). Published case fatality rates for levels 1,2 , and 4 were used. ${ }^{45}$ The figure for level 3 was expected to be midway between levels 2 and 4 . Sample size was predicted using an algorithm for detecting pairwise differences in groups using a binomial outcome variable. ${ }^{6}$ With roughly 400 patients at each level differences among levels could be detected at the $5 \%$ level of significance with $90 \%$ power. Alternatively, if there was no difference among levels 1,2 , and 3 a comparison at the $5 \%$ level between levels 1 and 4 with 400 subjects in each group would be able to detect a difference if the true case fatality rates were $7 \%$ and $14 \%$ respectively.

Univariate comparisons across levels for continuous variables were assessed by analysis of variance and covariance, and for categorical variables $\chi^{2}$ analysis and $\chi^{2}$ analysis of trend ${ }^{7}$ were employed. Standardised death rates (direct method) were used for presentation in tables but detailed multivaried analysis used logistic regression. The programs used were from the Biomedical data package. ${ }^{8}$

\section{Results}

There were 2266 definite or possible myocardial infarctions among the 2991 suspected attacks. The proportion of patients with definite or possible attacks (table II) decreased from level 1 to level 4, and this trend was significant $(p<0.05)$. The difference was not due to lack of diagnostic information. The proportions with a typical history of attack (average $72 \%$; $2140 / 2991$ ), two or more electrocardiograms (average $87 \%$; 2611/2991), or two or more cardiac enzyme results (average $86 \%$; 2578/2991) disclosed no trends which could account for the variable proportion of types of attack across levels. The remaining results are confined to the 2265 definite and

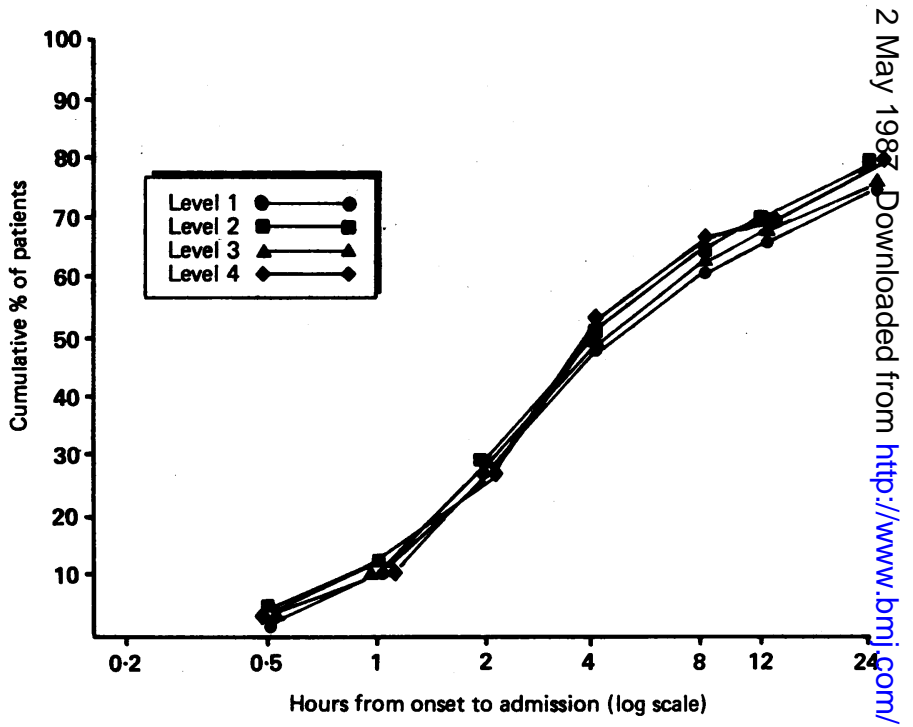

Cumulative distribution of time from onset of attack until admission to hospital $\frac{}{\mathrm{aP}}$ each level of care.

and the proportion at each level did not differ significantly. The median stâ of 11 days (11 days at levels 1 and 2,12 days at levels 3 and 4) was similat across levels. It appeared that patients at each level of care were similar.

The average overall unadjusted (crude) mortality at discharge (table III) $21 \%$ did not vary significantly across levels $\left(x^{2}=1 \cdot 1 ; d f=3 ; p>0 \cdot 75\right)$, and trend towards decreasing mortality in less elaborate hospitals was not significant $\left(x^{2}=0.7 ; \mathrm{df}=1 ; \mathrm{p}>0.95\right)$. The average mortality among patientso in coronary care units was lower $(17 \% ; 285 / 1654)$ but again showed nQ significant difference $\left(\chi^{2}=1 \cdot 0 ; d f=3 ; p>0.05\right)$ or a trend across leve $\left(\chi^{2}=0.9 ; \mathrm{df}=1 ; p>0.25\right)$. The mortality in the group treated in the ward feli by more than half from $41 \%(52 / 128)$ at level 1 to $20 \%(25 / 128)$ at level 4 . The differences in ward mortality across levels were significant $\left(\chi^{2}=14.9 ; \mathrm{df}=5\right.$ $p<0.01)$, as was the trend $\left(x^{2}=14.0 ; d f=1 ; p<0.001\right)$. The difference is mortality between coronary care unit and ward care was significant at levelo 1,2 , and 3 but not 4 . The difference was largest at level 1 and fet progressively to non-significance at level 4 . 
Age was an important determinant of mortality. For the whole cohort crude mortality was $62 / 731(8 \%), 140 / 752(19 \%)$, and $273 / 782(35 \%)$ for patients aged $<60,60-69$, and $\geqslant 70$ years, respectively. Adjustment of the crude mortality by age (table III) did not alter the significant results above, though the differences between unit and ward care at each level were reduced. The overall age adjusted mortality varied from $22 \%$ at level 1 to $19 \%$ at level 4 , which was not significant. Among the unit cases the difference across levels was even less.

To account for other known prognostic factors mortality was further adjusted using a composite severity score. ${ }^{9}$ This is similar to the more familiar Norris and Peel indices and includes age, extent of infarct, admission systolic blood pressure, pulse rate, cardiac failure, shock, and cardiac enzyme values. Table IV stratifies mortality at each level into five groups, the lowest score representing the lowest risk. This adjustment discloses no difference in severity standardised mortality among levels, either for hospitals as a whole or for coronary care units. The highest mortality was found in patients treated in wards at level 1 , which showed the largest difference between unit and ward care groups. The difference remained significant at levels 2 and 3 , though the magnitude was reduced. As before, there was no significant difference between the unit and ward care groups at level 4 . Further logistic analysis failed to show any benefit at higher levels of care for any particular subgroup based on severity, and the interaction term "level $\mathrm{x}$ severity" was not significant.

Two sources of bias may affect the comparisons in this study. The first may result from the referral of seriously ill patients to a highly elaborate hospital. Though this should be adjusted for by the measurement of severity of the attack, it may still cause a residual bias. The second may result from the transfer of patients from a less equipped hospital to another because of

TABLE III-Crude and age adjusted mortality ${ }^{\star}$ classified by site and level of care

\begin{tabular}{|c|c|c|c|c|c|c|c|}
\hline \multirow[b]{2}{*}{ Level of care } & \multicolumn{3}{|c|}{ Unit care } & \multicolumn{3}{|c|}{ Ward care } & \multirow{2}{*}{$\begin{array}{c}\text { Total } \\
\text { mortality } \\
(\%)\end{array}$} \\
\hline & $\begin{array}{l}\text { No of } \\
\text { cases }\end{array}$ & $\begin{array}{l}\text { No (\%) of } \\
\text { deaths }\end{array}$ & $\begin{array}{l}\text { Age adjusted mortality } \\
\text { (\%) }\end{array}$ & $\begin{array}{l}\text { No of } \\
\text { cases }\end{array}$ & $\begin{array}{l}\text { No (\%) of } \\
\text { deaths }\end{array}$ & $\begin{array}{l}\text { Age adjusted mortality } \\
(\%)\end{array}$ & \\
\hline $\begin{array}{l}1 \\
2 \\
3 \\
4\end{array}$ & $\begin{array}{l}449 \\
576 \\
415 \\
214\end{array}$ & $\begin{array}{r}71(16) \\
101(18) \\
73(18) \\
40(19)\end{array}$ & $\begin{array}{l}19 \\
20 \\
20 \\
20\end{array}$ & $\begin{array}{l}128 \\
198 \\
157 \\
128\end{array}$ & $\begin{array}{l}52(41) \\
67(34) \\
46(29) \\
25(20)\end{array}$ & $\begin{array}{l}39 \\
29 \\
25 \\
16\end{array}$ & $\begin{array}{l}21 \\
22 \\
21 \\
19\end{array}$ \\
\hline All hospitals & 1654 & $285(17)$ & & 611 & $190(31)$ & & 21 \\
\hline
\end{tabular}

^Directly standardised to total population.

TABLE IV-Mortality from definite and possible myocardial infarction in patients stratified by severity of attack (Bain prognostic score) and level of care for those managed in unit, ward, and hospitals as a whole

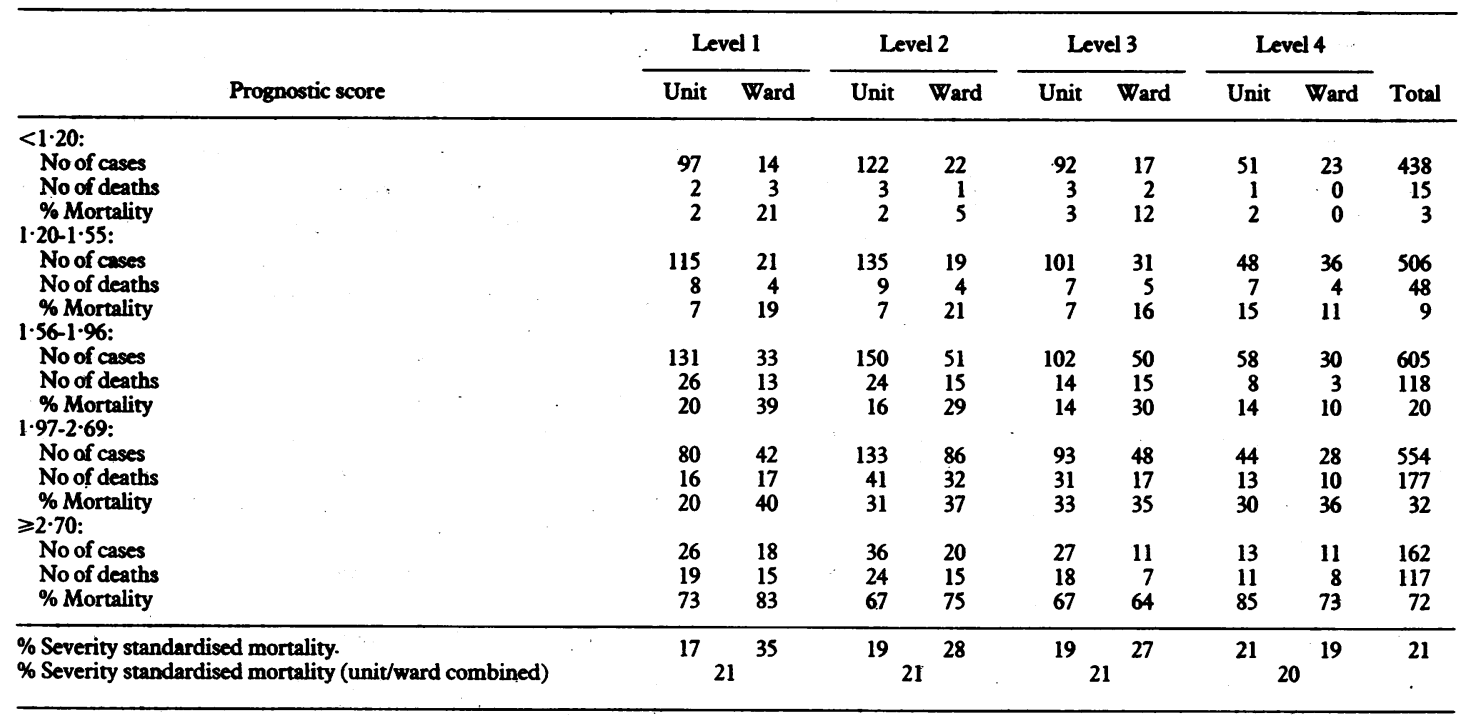

TABLE V-Prevalence of attempted cardiopulmonary resuscitation and rates of success overall and separately for unit and ward stratified by levels of care

\begin{tabular}{|c|c|c|c|c|c|}
\hline & Level 1 & Level 2 & Level 3 & Level 4 & Total \\
\hline \multicolumn{6}{|c|}{ Unit } \\
\hline $\begin{array}{l}\text { No of patients } \\
\text { No }(\%) \text { in whom resuscitation attempted } \\
\text { No }(\%) \text { in whom resuscitation successful }\end{array}$ & $\begin{array}{l}449 \\
83(18) \\
33(40)\end{array}$ & $\begin{array}{l}576 \\
114(20) \\
54(47)\end{array}$ & $\begin{array}{l}415 \\
79(19) \\
31(39)\end{array}$ & $\begin{array}{l}214 \\
42(20) \\
16(38)\end{array}$ & $\begin{array}{l}1654 \\
318(19) \\
134(42)\end{array}$ \\
\hline \multicolumn{6}{|c|}{ Ward } \\
\hline $\begin{array}{l}\text { No of patients } \\
\text { No }(\%) \text { in whom resuscitation attempted } \\
\text { No }(\%) \text { in whom resuscitation successful }\end{array}$ & $\begin{array}{l}128 \\
22(17)\end{array}$ & $\begin{array}{l}198 \\
20(10) \\
0\end{array}$ & $\begin{array}{l}157 \\
26(17) \\
0\end{array}$ & $\begin{array}{rr}128 & \\
12 & (9) \\
1 & (8)\end{array}$ & $\begin{array}{l}611 \\
80(13) \\
1(1)\end{array}$ \\
\hline \multicolumn{6}{|c|}{ Overall } \\
\hline $\begin{array}{l}\text { No of patients } \\
\text { No }(\%) \text { in whom resuscitation attempted } \\
\text { No }(\%) \text { in whom resuscitation successful }\end{array}$ & $\begin{array}{l}577 \\
105(18) \\
33(31)\end{array}$ & $\begin{array}{l}774 \\
134(17) \\
54(40)\end{array}$ & $\begin{array}{l}572 \\
105(18) \\
31(30)\end{array}$ & $\begin{array}{l}342 \\
54(16) \\
17(31)\end{array}$ & $\begin{array}{l}2265 \\
398(18) \\
135(34)\end{array}$ \\
\hline
\end{tabular}


complications. The first bias would spuriously inflate the mortality in more elaborate hospitals (levels 1 and 2), whereas the second would tend to reduce the mortality reported among the less equipped hospitals. To remove the effect of such biases the 107 patients who were referred were excluded and the 32 who were transferred were assumed to have died. The recalculated mortality did not produce significant differences in unit care or overall hospital care across levels.

A sensitive measure of a hospital's ability to manage patients effectively is the outcome of a cardiac arrest. In this study successful resuscitation of the patient meant leaving hospital alive. Overall the prevalence of attempted resuscitation and its successful outcome were not significantly different across levels (table V). The same was also true for patients managed in coronary care units. In the group treated in the ward the prevalence of attempted resuscitation was lower and successful resuscitation rare. The findings were unchanged when the analysis was restricted to patients under 70.

These data may be interpreted as evidence of less ability of wards successfully to resuscitate patients with cardiac arrest, accounting for higher mortality in ward care groups. Classifying the prevalence of attempted resuscitation and its success according to site, however, leads to different interpretation (table VI). Patients assigned to the unit care group who suffered an arrest were resuscitated with similarly high success in the casualty department, unit, or ward $\left(\chi^{2}=5.32 ; \mathrm{df}=2 ; 0.05<\mathrm{p}<0.1\right)$. By contrast, patients assigned to the ward care group did poorly whether resuscitation was attempted in the casualty department, unit, or ward. Hence it was the patient rather than the place of arrest which determined successful resuscitation.

TABLE VI-Prevalence of cardiac arrest and rate of success according to site of arrest

\begin{tabular}{ccc}
\hline & \multicolumn{2}{c}{ Management group } \\
\cline { 2 - 3 } Site of arrest and resuscitation & $\begin{array}{c}\text { Unit } \\
(\mathrm{n}=1654)\end{array}$ & $\begin{array}{c}\text { Ward } \\
(\mathrm{n}=611)\end{array}$ \\
\hline Casualty department: & $62(4)$ & $4(1)$ \\
No $(\%)$ in whom resuscitation attempted & $34(55)$ & 0 \\
No $(\%)$ in whom resuscitation successful & $216(13)$ & $6(1)$ \\
Unit: & $83(38)$ & 0 \\
No $(\%)$ in whom resuscitation attempted & $40(2)$ & $70(11)$ \\
No $(\%)$ in whom resuscitation successful & $17(43)$ & $1(1)$ \\
Ward: & & \\
No $(\%)$ in whom resuscitation attempted & &
\end{tabular}

\section{Discussion}

This study did not detect any differences in hospital mortality from acute myocardial infarction among levels of care. Further, no trend in mortality was evident across levels. There was also no subgroup of patients who could be distinguished on the basis of severity of attack who had a significantly better outcome in more elaborate hospitals. Though a Bain severity index' was used, reanalysis using both the Peel and Norris indices ${ }^{111}$ did not alter these results. Successful resuscitation after a cardiac arrest is another determinant of effective care. The average rate of successful resuscitation (31\%) was similar across levels. Had resuscitation of patients with primary ventricular fibrillation (presumably those with a lower prognostic score) been more effective at higher levels of care a difference in mortality within severity strata would have been evident.

The study found an average mortality of $21 \%$ and had been designed to detect differences in mortality ranging from $7 \%$ at level 1 to $35 \%$ at level 4 . These were large differences and possibly larger than should have been expected. The study found a difference in mortality of $1 \%$ between levels 1 and 4 with a confidence interval of $-4 \%$ to $6 \% .^{7}$ Had the true difference been as high as $7 \%$-for example, $15 \%$ and $22 \%$, respectively-the study was large enough to detect this difference at the $5 \%$ level (one sided) with $80 \%$ confidence. If a smaller difference truly existed then the study would have detected it only with lower levels of significance or confidence, or both.

These comparisons were among hospitals grouped according to factors that would tend to distinguish the refinement of care received and hence skill in managing patients with cardiac disease. Alternative groupings by size of hospital (number of beds), type (university teaching, major hospital, and local communityds or location (urban and rural) would not significantly alter the order of levels of care. Reanalysis of mortality using these othe्f classifications produced no significant differences.

Our findings are consistent with those of other studies tha compared mortality in different types of hospital. They agree wit the retrospective studies of Bloom and Peterson ${ }^{12}$ and Bain et al, ${ }^{9}$ but the study failed to find a subgroup of moderately ill patients whis might benefit from more elaborate care. We did not find a worse prognosis for patients treated in more advanced hospitals. ${ }^{13} \mathrm{~T}$ ? results support work suggesting that increased expenditure for coronary care facilities does not lead to reduced hospital mortality Our findings do not exclude the possibility that a still less refin level of care may be less effective. Nevertheless, the study includef all hospitals within a health region that admitted more tham 40 patients with myocardial infarction a year. The proportion of acute attacks managed in still smaller and less equipped hospitass would be small.

It appears that effective care of patients is possible within the range of hospital facilities currently available. If a difference $\overrightarrow{\mathrm{v}}$ outcome between care in a medical ward and care in a coronary unif truly existed when coronary care units were first introduced, then types of hospitals have now benefited. Effective resuscitation byia well run cardiac arrest service in a hospital without a coronary cale unit was described many years ago by Norris et al. ${ }^{15}$ Changing patterns of hospital referral with increasing numbers of low rigig patients ${ }^{16}$ may have obscured the effectiveness of coronary care units. Against this, our study did not find a subgroup stratified b severity who fared better in more elaborate hospitals.

At levels 1,2 , and 3 the significant difference in mortalif between unit and ward care agrees with studies by Hofvendahl ${ }^{17}$ and Christiansen et al. ${ }^{18}$ The significant difference was not found by $\mathrm{H}$. et al, ${ }^{19}$ who suggested that improved management in medical wards after the introduction of coronary care units had led to no differen in effective care. We found that the difference between unit and ward care varies across levels. It is largest at level 1 and disappears gl level 4. The overall hospital mortality is the same at each leve suggesting that the observed difference between unit and waf mortality may be due to unrecognised biases such as patiegt selection. There is evidence for a selection bias because patien treated in the unit were slightly younger and had less severe infarctions. The criteria for selection for unit or ward care plainß differed because $80 \%$ of patients with suspected myocardia infarction were treated in the unit at level 1 and only $60 \%$ at level $\frac{7}{8}$ The finding that overall hospital mortality did not differ among levels when possible selection bias and confounding factors we considered strongly suggests that the difference between unit and ward care within levels was due to other, unrecognised sources bias. Further evidence for this selection process within hospitals $\frac{115}{5}$ derived from table VI, where the ability successfully to resuscitage patients depends on the clinical assignment to unit or ward care rather than the place of occurrence of the cardiac arrest.

This study was not a randomised trial, and despite efforts control the known sources of bias those unrecognised could not by controlled. A randomised controlled trial would be desirable reduce the risk of such biases. Nevertheless, the experience of the only two randomised studies illustrates the problem of this desigh to determine the effectiveness of coronary care units. ${ }^{20-22}$ Boff studies drew criticism because of delayed management before randomisation leading to the assignment of low risk patients, t@ few patients to detect differences, and, most important, the exclusion of $25 \%$ or more of patients considered to require hospitaf care. ${ }^{23}$ In both cases the patients excluded were those in whom ${ }^{2}$ benefit was thought most likely on clinical grounds. In our study the fact that more elaborate units were found in city hospitals where the less elaborate ones were found in country hospitals would make it difficult and probably unethical to randomise patients to differem levels of care. Furthermore, the relative isolation of many of the hospitals created a natural experiment without the ethical dilemmos of a clinical trial. 
The results of this study should suggest to both health administrators and clinicians that increased resources for coronary care, either for new services or for upgrading existing services, may not be required. Our findings also highlight the potential value of research designed to develop strategies to increase the efficiency of coronary care facilities by improving the selection process for such care. ${ }^{24} 25$

\section{References}

1 Goldman L. Coronary care units. A perspective on their epidemiological impact. Int $\mathcal{f}$ Cardio 1982;2:287-91.

World Health Organisation. Myocardial infarction community registers. Regional office for Europe, Copenhagen, 1976. Public Health in Europe 1977;5:1-232.

3 Joint International Society and Federation of Cardiology/World Health Organisation Task Force on Standardisation of Clinical Nomenclature. Nomenclature and criteria for diagnosis of ischemic heart disease. Circulation 1979;59:607-8.

4 O'Rourke MF, Walsh B, Fletcher M, Crowley A. Impact of the new generation coronary care unit. Br Med f 1976;ii:837-9.

National Heart Foundation, Australia. Coronary care unit survey 1980. Sydney: National Heart Foundation, 1980 .

6 Casagrande JT, Pike MC. An improved formula for calculating sample sizes for comparing two binomial distributions. Biometrics 1978;34:483-6.

7 Armitage P. Statistical methods in medical research. Oxford and Edinburgh: Blackwell Scientific, 1971:207-13, 387.

8 Engelman L. Stepwise logistic regression. In: Dixon WJ, ed. BMDP statistical software. Berkeley: University of California Press, 1981:330-4.

Bain C, Siskind V, Neilson G. Site of care and survival after acute myocardial infarction. Med $\mathcal{J}$ Aust 1981;ii:185-8.
10 Peel AAF, Semple I, Wang I, Lancaster WM, Dall JLG. A coronary prognostic index for grading the severity of myocardial infarction. Br Hean $\mathcal{f} 1962 ; 24: 745-60$.

11 Norris RM, Brandt PWT, Caughey DE, Lee AJ, Scott PJ. A new coronary prognostic index. Lancet 1969;i:274-8.

2 Bloom BS, Peterson OL. End results, cost and productivity of coronary care units. N Engl f Med 1973;277:72-8.

13 Gordis L, Naggan L, Tonascia J. Piffalls in evaluating the impact of a coronary care unit on mortality from myocardial infarction. Johns Hopkins Medical foumal 1977;141:287-95.

14 Goldman L, Cook F, Hashimoto B, Stone P, Muller J, Loscalzo A. Evidence that hospital care for acute myocardial infarction has not contributed to the decline in coronary mortality between acute myocardial infarction has not contributed to the

15 Norris RM, Brandt PWT, Lee AJ. Mortality in a coronary care unit analysed by a new prognostic index. Lancet 1969;ii:278-81.

16 Rose G. The contribution of intensive coronary care. British foumal of Preventive and Social Medicine 1975;29:147.

7 Hofvendahl S. Influence of treatment in a CCU on prognosis in acute myocardial infarction. Acta Med Scand 1971;519(suppl):1-78.

18 Christiansen I, Iversen K, Skouby AP. Benefits obtained by the introduction of a coronary care unit: a comparative study. Acta Med Scand 1971;189:285-91.

19 Hill JD, Holdstock G, Hampton JR. Comparison of mortality of patients with heart attacks admitted to a coronary care unit and an ordinary medical ward. $\mathrm{Br}$ Med $\mathcal{f}$ 1977;ii:81-3.

20 Mather HG, Pearson NG, Read KLQ, et al. Acute myocardial infarction: home and hospital treatment. Br Med f 1971;iii:334-8.

21 Mather HG, Morgan DC, Pearson NG, et al. Myocardial infarction: a comparison between home and hospital care for patients. Br Med F 1976;i:925-9.

22 Hill JD, Hampton JR, Mitchell JRA. A randomised controlled trial of home-vs-hospital management for patients with suspected myocardial infarction. Lancet 1978;i:837-41.

23 Rawles JH, Kenmure ACF. The coronary care controversy. BrMed f 1980;281:783-6.

24 Pozen MW, D'Agostino RB, Mitchell JB, et al. The usefulness of predictive instrument to reduce inappropriate admissions to the coronary care unit. Ann Intern Med 1980;92:238-42.

25 Goldman $L$, Weinberg $M$, Weisberg $M$, et al. A computer derived protocol to aid in the diagnosis of emergency room patients with acute chest pain. $N$ Engl f Med 1982;307:588-96.

(Accepted 12 February 1987)

\title{
Housing conditions and ill health
}

\author{
CLAUDIA J MARTIN, STEPHEN D PLATT, SONJA M HUNT
}

\begin{abstract}
Lack of empirical evidence that living in damp houses has detrimental effects on health may partly be due to inadequate research. A preliminary study was therefore carried out of a random sample of council owned residences in a deprived area of Edinburgh, a respondent from consenting households being interviewed to obtain a profile of the physical and mental health of all adults and children. In addition, information was gathered about other factors that might be important, particularly smoking and selective bias in the allocation of tenants to houses. Independent measures of dampness were made by environmental health officers.

No conclusive effects of damp on the health of adults were identified. Nevertheless, children living in damp houses, especially where fungal mould was present, had higher rates of respiratory symptoms, which were unrelated to smoking in the household, and higher rates of symptoms of infection and stress.

Housing should remain an important public health issue, and the effects of damp warrant further investigation.
\end{abstract}

\footnotetext{
Research Unit in Health and Behavioural Change, University of Edinburgh, Edinburgh EH1 2QZ

CLAUDIA J MARTIN, MA, PHD, research fellow

SONJA M HUNT, MA, PHD, senior research fellow

MRC Unit for Epidemiological Studies in Psychiatry, Royal Edinburgh Hospital, Edinburgh EH10 5HF

STEPHEN D PLATT, MSC, PHD, research sociologist

Correspondence to: Dr Martin.
}

\section{Introduction}

The $B M F$ argued recently that the health implications of poverty, unemployment, and inadequate housing were not being emphasised strongly enough and made a plea for the formation of a public health alliance to highlight these issues. ${ }^{1}$ Certainly, the role of housing conditions in the aetiology of illness appears to have received comparatively little attention since the decline of tuberculosis in the 1950s.

Most recent studies of housing conditions have concentrated on the relation between living in a damp house and respiratory complaints such as asthma ${ }^{2}$ and wheeze. ${ }^{34}$ Rising and penetrating damp provide the moist conditions conducive to germination of spores of mould fungi. Fungal spores, in turn, are believed to affect the respiratory tract by producing lesions in tissue, by forming saprophytic colonies on plugs of mucus, and by acting as allergens causing rhinitis, alveolitis, and asthma. ${ }^{56}$ Some studies have suggested that ambient humidity influences the viability of viruses in droplet sprays. ${ }^{7.9}$ The association between damp housing and health problems, however, is not clear cut, possibly being complicated by other factors known to affect health, such as smoking and poverty. A further serious flaw has been that the presence of damp has been reported by the householder or by the research team, casting doubt on the objectivity of the findings because of either the tenant's desire to get rehoused or bias in the experimenter.

This study was carried out in response to the concern of residents in a deprived area of Edinburgh about the possible effects of damp on their health. The preliminary study aimed at investigating the relation between damp housing and the physical and mental health of tenants and their children.

Edinburgh city is ringed by estates of council housing of varying quality and desirability, and the study area is regarded as one of the less (but by no means least) desirable in which to live ( $K$ Brown, unpublished master's dissertation, 1986). The area consists of 